\title{
A Comparison of Secretory Actions of VIP, Secretin and CCK-PZ in the Isolated and Perfused Kitten Pancreas
}

\author{
Tomio KANNO And Atsushi SAITO
}

\author{
Department of Physiology, Faculty of Veterinary Medicine, \\ Hokkaido University, Sapporo 060, Japan
}

\begin{abstract}
Synopsis
Secretory actions of VIP (vasoactive intestinal peptide), secretin and CCK-PZ (Cholecystokinin-pancreozymin) were compared in the isolated and perfused kitten pancreas. Perfusion of the isolated kitten pancreas with a solution containing 20 $\mathrm{mU} / \mathrm{m} l$ CCK-PZ resulted in gradual hyperpolarization of the pancreatic acinar cell. CCK-PZ induced a dose-dependent increase in the pancreatic protein output and a small but definite increase in the flow of pancreatic juice which was also dose dependent upon CCK-PZ. Secretin and VIP induced a dose-dependent increase in the flow but a negligible increase in the pancreatic protein output. The estimated $\mathrm{ED}_{50}$ for VIP was $1.5 \mathrm{nM}$ which was 5 times as large as the estimated $\mathrm{ED}_{50}$ for secretin. A considerable amount of VIP, which corresponded roughly to the activity of exogenous $0.6 \mathrm{nM}$ VIP, was spontaneously released from the isolated kitten duodenum into the portal vein, and this VIP release was nullified during vascular perfusion with a Ca-deficient solution. With respect to these and other results, we will propose a view concering a possible role of VIP in controlling the function of the execrine pancreas.
\end{abstract}

VIP resembles secretin and glucagon in its chemical structure (see Bodanszky, 1977), and stimulates the exocrine pancreas to increase the pancreatic juice flow rich in bicarbonate (Makhlouf, et al., 1974). Knoturek, et al., (1976) examined this effect of VIP in chronic pancreatic fistula of cats and dogs, and concluded that VIP in cat was a secretin-like full agonist and in dogs a partial agonist of pancreatic bicarbonate secretion. Since VIP also possesses direct vasodilatator activity (Kitamura et al., 1975; Said \& Mutt, 1970; Mailman, 1978), it is possible that at least some part of the pancreatic responses in situ might have been secondary to dilatation of the blood vessels supplying the pancress. The present experiments were undertaken to test the direct secretory effect of VIP in the isolated kitten pancreas under constant vascular flow.

\section{Materials and Methods}

\section{Isolation and perfusion of the pancreas}

Isolated and perfused kitten pancreas with the attached duodenum was prepared in accordance with the procedure adopted in the rat preparation (Kanno et al., 1976). Male and female kittens weighing about $600 \mathrm{~g}$ and aged about 2 months were deprived of food but allowed water for $24 \mathrm{hr}$ before the experiments. After anaethesia with pentobarbital sodium $(30 \mathrm{mg} / \mathrm{kg}$ body weight), the vascular system was cannulated and perfused. The rate of vascular flow was kept constant at $3 \mathrm{~m} l / \mathrm{min}$.

\section{Drugs and solution}

The composition of the standard Krebs-Henseleit solution used for perfusing and bathing the prepa- 


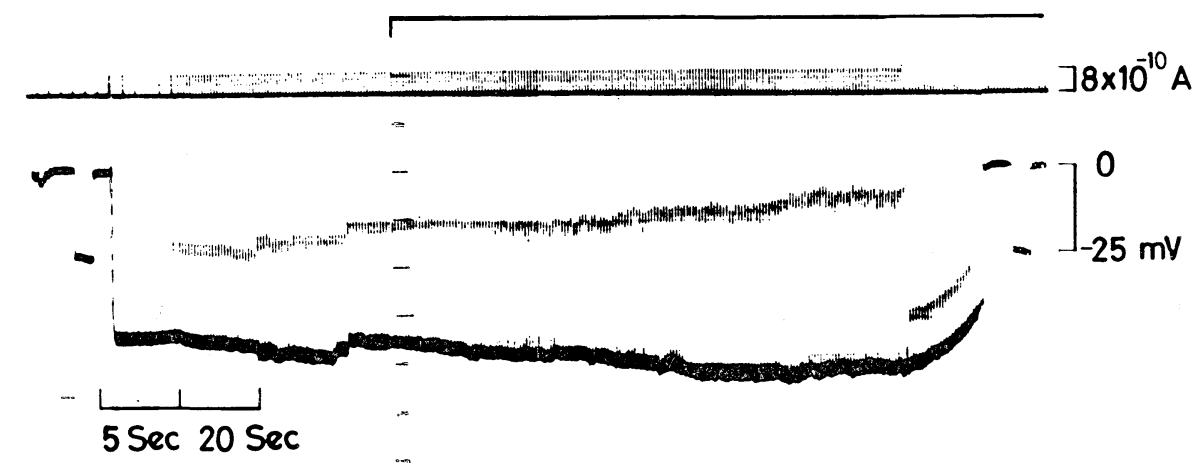

Fig. 1. An example of a recording of the membrane potential of a pancreatic acinar cell with superimposed displacements resulting from passage of current pulses (50 mses duration) through the recording electrode via the Wheatstone bridge circuit. The bar above the current recording indicates the period of perfusion of the isolated kitten pancreas with the Krebs-Henseleit sclution containing $20 \mathrm{mU} / \mathrm{m} l$ CCK-PZ.

ration was as foliows $(\mathrm{mM}): \mathrm{NaCl}, 131 ; \mathrm{KCl}, 5.6$; $\mathrm{CaCl}_{2}, 2.5 ; \mathrm{MgCl}_{2}, 1.0 ; \mathrm{NaH}_{2} \mathrm{PO}_{4}, 1.0 ; \mathrm{NaHCO}_{3}$, 25 ; glucose 5.0. The solution was equilibrated with $5 \% \mathrm{CO}_{2}$ in $\mathrm{O}_{2}$ and had a $\mathrm{pH}$ of about 7.4. Synthetic pcrcine VIP was kindly donated by Prof. N. Yanaihara of the Laboratory of Bioorganic Chemistry, Shizuoka College of Pharmacy. VIP, pure natural porcine CCK-PZ $(3500 \mathrm{U} / \mathrm{mg}$, GIH research Unit, Karolinska Institute, Stockholm) and synthetic porcine secretin (Schwarz/Mann, New York) were injected through a cannula into the inlets of the vascular perfusion. The digestive enzymes and flow of pancreatic juice were estimated as reported previously(Kanno et al., 1976).

\section{Electrical recordings}

Transmembrane potential and effective membrane resistance of the pancreatic acinar cell were recorded simultaneously by a manually advancing $\mathrm{KCl}$-filled micro-elecrode, through which a current of $50 \mathrm{msec}$ in duration was passed in order to polarize the cell. A full description of the procedure has been given in a previous report (Kanno, 1972).

\section{Statistics}

Results are expressed as mean \pm S.E. and are analyzed by Student's $t$ test.

\section{Results}

Earlier papers have shown that perfusion with Krebs-Henseleit solution containing CCK-PZ produced hyperpolarization of the acinar cells and increased amylase output from the isolated rat pancreas (Kanno, 1972, 1975: Kanno and Saito, 1976). The present experiment confirmed the effects during perfusion of the isolated kitten pancreas with a solution containing $20 \mathrm{mU} / \mathrm{m} l$ (1.5 nM) CCK-PZ. Fig. 1 shows a typical recording of the intracellular membrane potential and effective membrane resistance from an acinar cell of the perfused kitten pancreas. Perfusion with the solution containing $20 \mathrm{mU} / \mathrm{m} l$ CCK-PZ resulted in gradual hyperpolarization from $-50 \mathrm{mV}$ to the maximum value of $-60 \mathrm{mV}$ after $1.5 \mathrm{~min}$ from the initiation of perfusion and this change was accompanied by a gradual increase in effective membrane resistance (Fig. 1).

Dose-response relations for the secretagogues-induced secretory resonses were ob- 


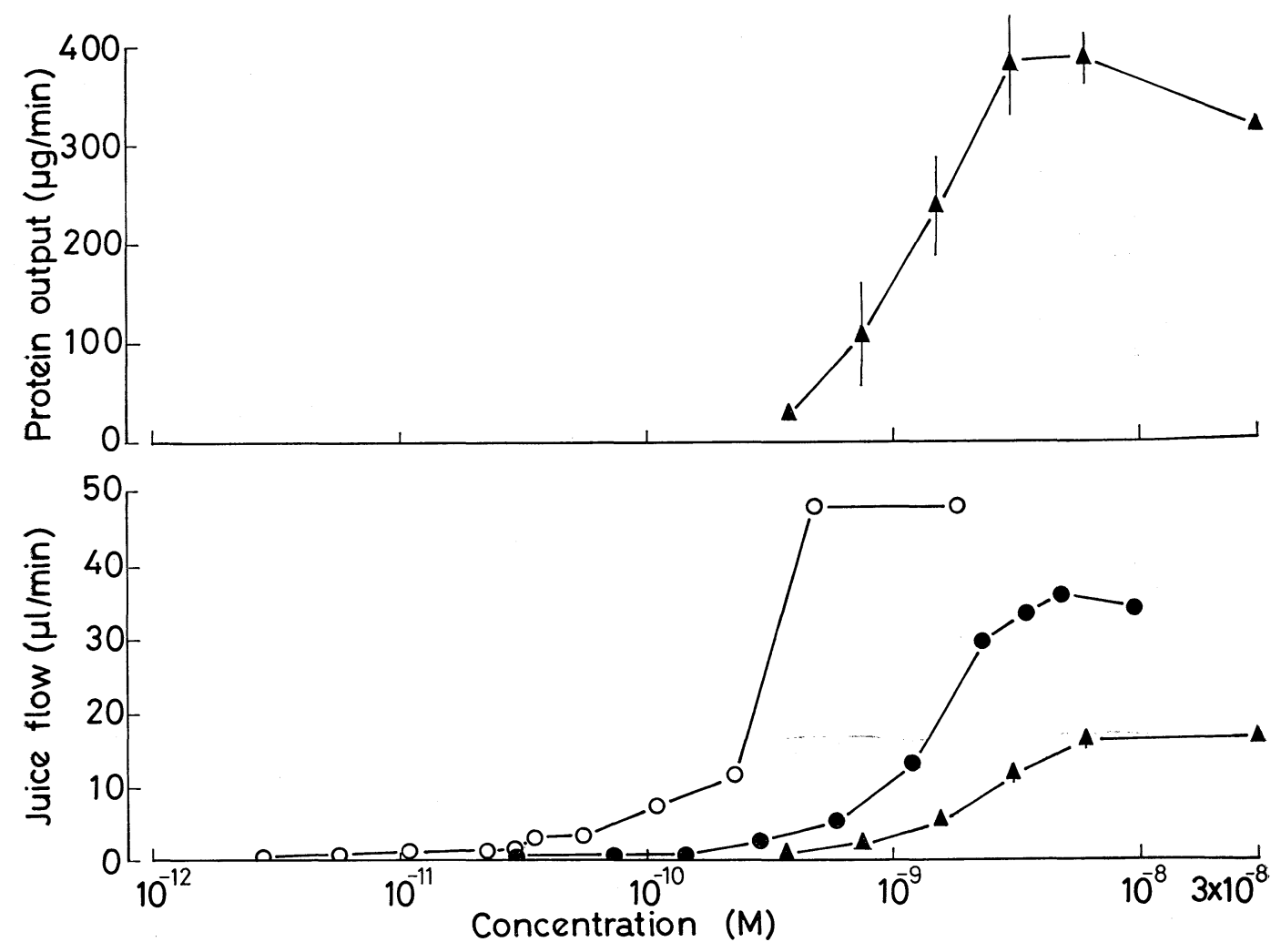

Fig. 2. The pancreatic protein outputs and juice flows in response to graded doses of secretin (O), VIP ( $)$ and CCK-PZ ( $\wedge$ in the isolated and perfused kitten pancreas. Each point of CCK-PZ is a mean $( \pm$ S.E.) of five experiments, and those of secretin and VIP are obtained from two preparations respectively.

tained in the isolated and perfused kitten pancreas. In these experiments, increasing concentrations of CCK-PZ $(0.3,0.8,1.5,3$ and $6 \mathrm{nM})$, secretin $(0.003,0.006,0.01,0.02$, $0.03,0.05,0.06,0.1,0.2,0.5$ and $1.8 \mathrm{~nm})$ or VIP $(0.03,0.07,0.2,0.3,0.6,1.2,2.4$, $3.4,4.7$ and $9.5 \mathrm{~nm}$ ) were used in series to stimulate the preparation for $10 \mathrm{~min}$ at intervals of 30 to $60 \mathrm{~min}$. The sums of protein output and pancreatic juice flow in the samples collected for $10 \mathrm{~min}$ during stimulation with each secretagogue were plotted against the logarithmic scale of the concentration of each secretagogue used (Fig. 2). To display the characteristics of secretagogues in a more precise manner, the following values and responses are listed in Table 1 : the effective dose needed to produce half the maximum response $\left(\mathrm{ED}_{50}\right)$, a dose producing the maximum response, the maximum response, $\mathrm{Ca}$ dependency of the response, $\mathrm{Na}$ dependency of the response and $\mathrm{K}$ dependency of the response. In Table 1, the corresponding values and responses obtained in the isolated and perfused rat pancreas are also listed.

We have recently reported that a considerable amount of immunoreactive VIP is spontaneously released from the isolated duodenum of kitten into the portal vein, and that the VIP release is nullified when the vascular system of the duodenum is per- 


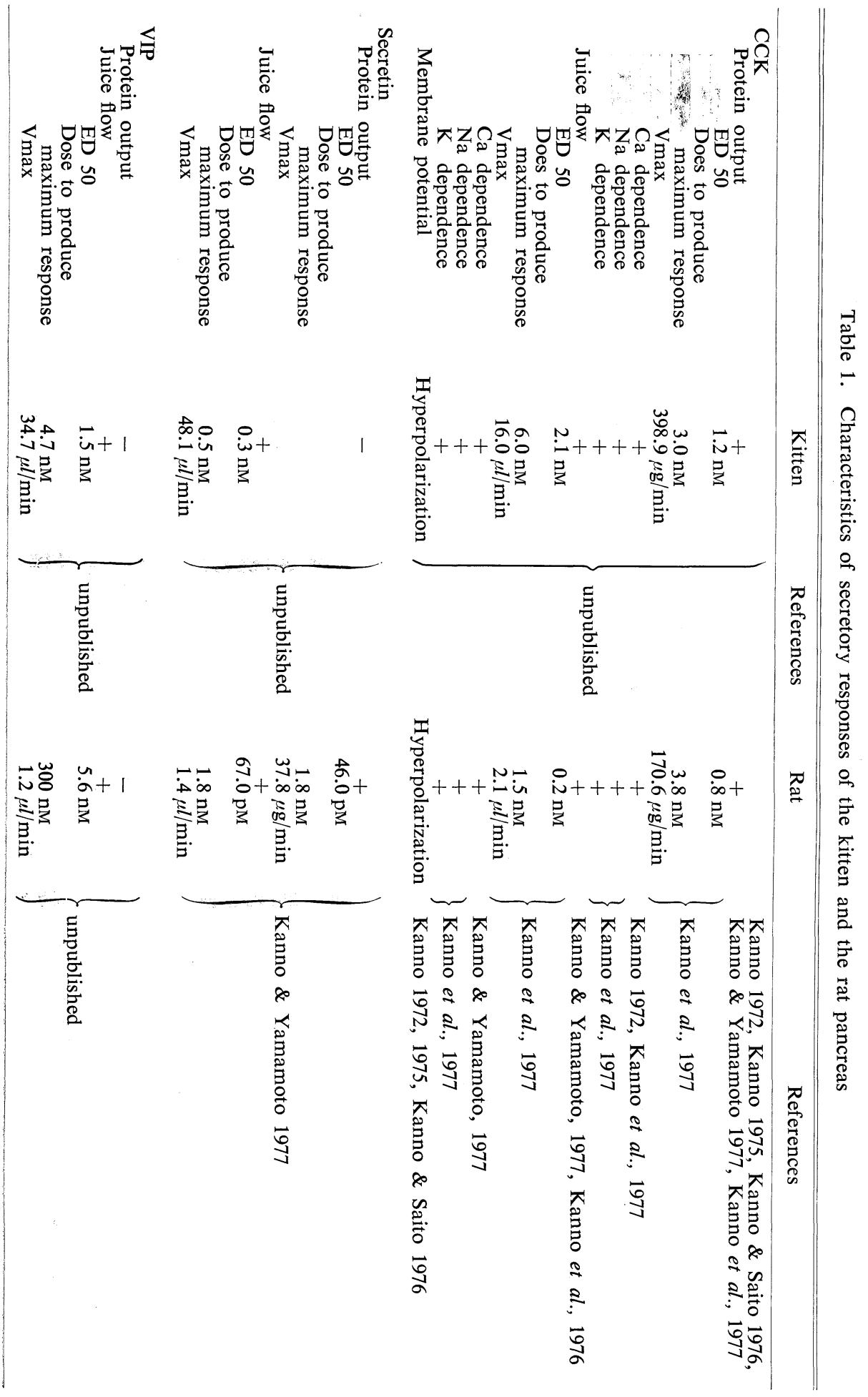



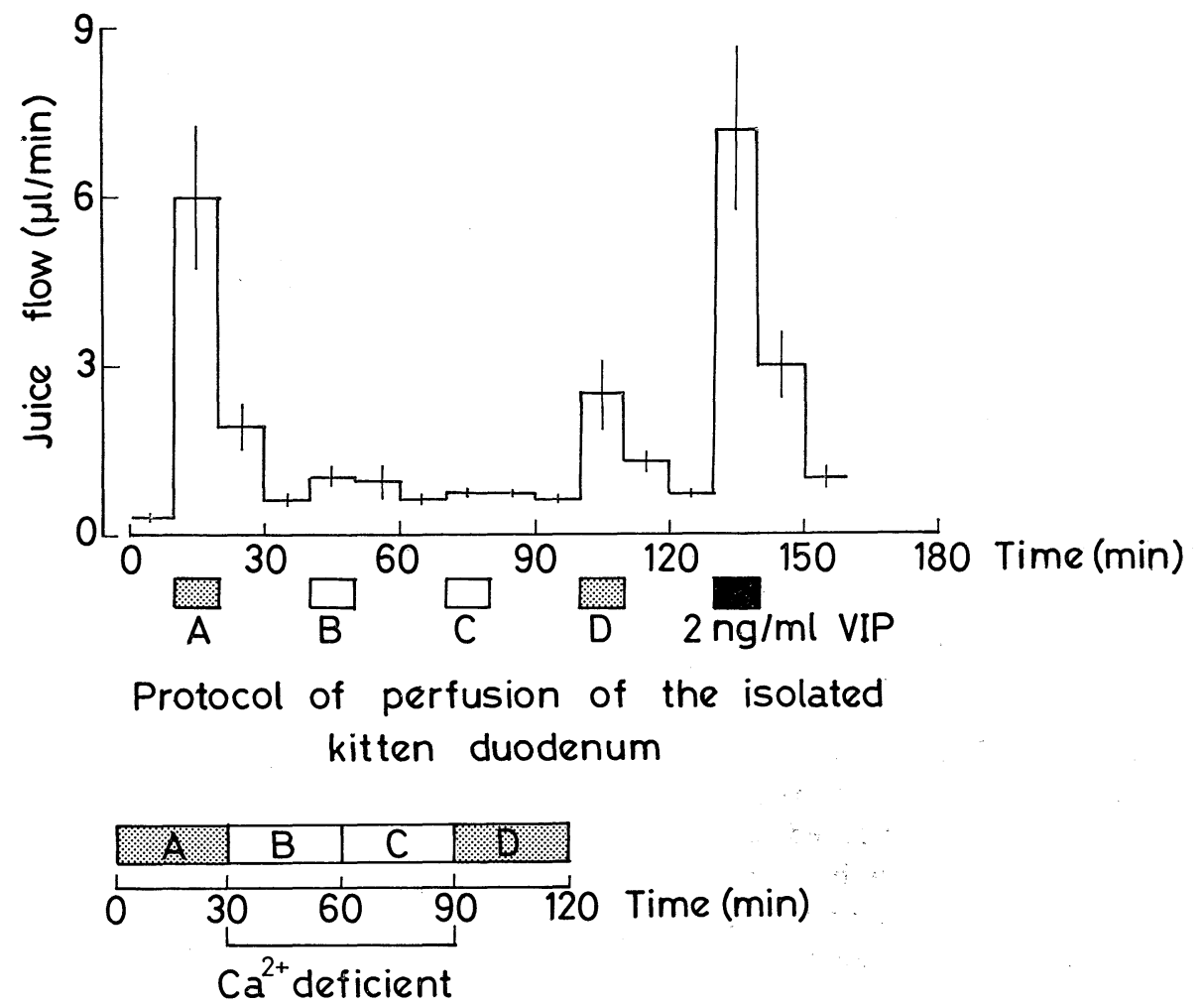

Fig. 3. Bioassay of VIP activity of venous perfusate collected from the portal vein of pancreaticoduodenal preparation of the kitten without any secretagogue in the duodenal lumen. The VIP activity of the venous perfusate was estimated in the isolated and perfused kitten pancreas. Per. fusates lettered $A$ and $D$ were collected when the pancreaticoduodenal preparation was perfused with the standard Krebs-Henseleit solution before and after the perfusion with the Ca-deficient solution. Perfusates lettered $\mathrm{C}$ and $\mathrm{D}$ were collected when the pre aration was perfused with the Ca-deficient solution. The final response was induced by $2 \mathrm{ng} / \mathrm{m} l$ exogenous VIP infusion, which is represented by a solid horizontal bar. Each value represents the mean ( \pm S.E.) for five experiments.

fused with a Ca-deficient solution (Kanno, et al., 1979). This has been confirmed by a bioassay of VIP in the isolated and perfused kitten pancreas: (1) the amount of spontaneous VIP release was enough to induce a clear increase in pancreatic juice flow in the isolated kitten pancreas, (2) the response induced by the spontaneous VIP release corresponded roughly to that induced by exogenous $0.6 \mathrm{nM}$ VIP, and (3) the spontaneous VIP release was nullified during vascular perfusion with a Ca-deficient solution (Fig. 3).

\section{Discussion}

The isolated and perfused preparation of the pancreas offers several advantages over experiments on the intact animal: the preparation is free from the effect of the humoral factors as well as the autonomic nervous system, and it is possible to control the flow, the chemical components and the concentration of the perfusion medium (see Scratcherd and Case, 1973). The secretory actions of CCK-PZ, secretin and VIP were 
compared, in the isolated and perfused kitten pancreas. The present experiments have shown that CCK-PZ increases pancreatic enzyme output as well as pancreatic juice flow, and that both secretory responses are inhibited in $\mathrm{Ca}, \mathrm{Na}$, and $\mathrm{K}$ deficient environments. The present experiments have also demonstrated that CCK-PZ hyperpolarizes the pancreatic acinar cell. These results accurately coincided with those obtained in the isolated and perfused rat pancreas (Kanno, 1972, 1975; Kanno and Saito 1976, 1978 ; Kanno et al., 1977).

In rat pancreas, it was shown that secretin induced a dose-dependent increase in the flow of pancreatic juice and a slight but definite increase in amylase output which was also dependent upon the dose of secretin (Kanno and Yamamoto, 1977). In the kitten pancreas, the present experiments have shown that secretin induced a dosedependent increase in the flow but a negligible increase in the pancreatic protein output except for a transient increase which may quite well be due to flushing of the pancreatic protein retained in the ductal lumen.

In the kitten pancreas, the maximum flow induced by VIP was about $70 \%$ of that obtained with secretin, and the estimated $\mathrm{ED}_{50}$ for VIP was $1.5 \mathrm{~nm}$ which was 5 times as large as that estimated for secretin. These data show that VIP has much lower efficacy than secretin, and are consistent with those reported by other investigators (Dockray, 1973; Makh- louf et al., 1974 ; Konturek et al., 1975, 1976; Robberecht et al., 1976). This may not necessary mean the action of VIP on the pancreatic juice flow is pharmacological. It is known that VIP is localized in the pancreas to nerves associated with the islets, the acini, and the ducts (Larsson et al., 1976; Buffa et al., 1977; Sundler, et al., 1978), and that stimulating the high threshold nerve fibers produces a significant increase in venous plasma VIP concentration in the cat (Fahrenkrug et al., 1978). Thus
VIP may exert its action by release from nerve terminals, and the VIP level in the venous plasma may represent an overflow (Jensen et al., 1978). The VIP level in the venous plasma in the anaesthetized and atropinized cat was raised up $0.27 \mathrm{~nm}$ after vagus nerve stimulation (Fahrenkrug, et al., 1978), and this level induced a moderate increase in pancreatic juice flow in the isolated and perfused kitten pancreas. Even the resting level of spontaneous VIP release is enough to produce a certain increase the in flow in the isolated kitten pancreas. On the other hand in the isolated and perfused rat pancreas, VIP has the lowest efficacy when compared with the efficacy of VIP in the kitten. This may mean that VIP may play only a slight role if any at all in controlling the function of the exocrine pancreas in the rat.

It is known that the resting level of pancreatic juice flow of kitten and cat under anaesthesia is very low although a rather large amount of pancreatic enzymes are flushed out in accordance with a increase in pancreatic juice flow. Taking these facts into consideration, we propose the following view as to a physiological role of the nerve fibers that secrete VIP in the cat: the VIP nerve may be activated either by reflex or cephalic mechanism, and VIP in turn may initiate a flushing of the pancreatic digestive enzymes retained in the lumen of terminal duct in co-operation with the simultaneous relaxation of the Oddi's sphincter.

\section{Acknowledgement}

We thank Prof. N. Yanaihara, Shizuoka College of Pharmacy, for the generous gift of synthetic VIP. The investigation was supported by grants to one of the authors (T. K.) from the Ministry of Education, Science and Culture, Japan, and Mitsubishi, Foundation, Japan. 


\section{References}

Bodanszky, M. First International Symposium on Hormonal Receptors in Digestive Tract Physiology, INSERM Symposium. No. 3 (edited by S. Bonfils, P. Fromageot and G. Rosselin). North-Holland, Amsterdam (1977).

Buffa, R., C. Capella, E. Solcia, B. Frigerio and S. I. Said (1977). Histochemistry 50, 217.

Dockray, G. Y. (1973). Experientia 29, 1510.

Fahrenkrug, J., U. Haglund, M. Jodal, O. Lundgren, L. Olbe and O. B. Schaffalitzky de Muckadell (1978). J. Physiol. (Lond.) 284, 291.

Jensen, S. L., J. Fahrenkrug, J. J. Holst, O. Vagn Nielsen and O. B. Schaffalitzky de Muckadell (1978). Am. J. Physiol. 235, E387.

Kanno, T. (1972). J. Physiol. (Lond.) 265, 353.

Kanno, T. (1975). ibid. 245, 599.

Kanno, T. and A. Saito (1976). J. Physiol. (Lond.) 261, 505 .

Kanno, T. and Saito (1978). ibid. 251, 263.

Kanno, T. and M. Yamamoto (1977). ibid. 264, 787. Kanno, T., A. Saito and Y. Sato (1977). ibid. 270, 9. Kanno, T., T. Suga and M. Yamamoto (1976). Jap.
J. Physiol. 26, 101.

Kanno, T., Saito, A., Yonezawa, H., Sato, H. Yanaihara, C. and Yanaihara, N. (1979). Gut Peptides (edited by A. Miyoshi). Kodansha Ltd., Tokyo.

Kitamura, S., T. Yoshida and S. I. Said (1975). Proc. Soc. exp. Biol. Med. 148, 25.

Konturek, S. J., A. Pucher and T. Radecki (1976). J. Physiol. (Lond.) 255, 497.

Konturek, S. J., P. Thor, A. Dembinski and R. Krol (1975). Gastroenterology 68, 1527.

Konturek, S. J., S. Domschke, W. Domschke, A. Dembinski, R. Król and L. Demling (1976). $J$. Lab. Clin. Med. 88, 608.

Larsson, L.-I., J. Fahrenkrug, O. B. Schaffalitzky de Muckadel, F. Sundler, R. Håkanson and J. F. Rehfeld (1976). Proc. Natl. Acd. Sci. US. 73, 3197.

Mailman, D. (1978). J. Physiol. (Lond.). 279, 121.

Makhlouf, G. M., S. I. Said and W. M. Yan (1974), Gastroenterology 66, 737.

Robberecht, P., T. P. Conlon and J. D. Gardner (1976). J. Biol. Chem. 251, 4635.

Said, S. I and V. Mutt (1970). Nature 225, 863.

Scratcherd, T. and R. M. Case (1973). Gut 14, 592.

Sundler, F., J. Alumets, R. Håkanson, J. Fahrenkrug and O. B. Schaffalitzky de Muckadell (1978). Histochemistry 55, 173. 